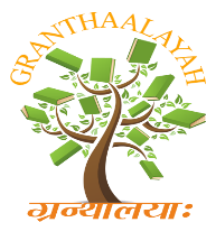

INTERNATIONAL JOURNAL OF RESEARCH GRANTHAALAYAH A knowledge Repository

\title{
HOW WE CAN BRING THE CHANGE IN SOCIETY USING ECO-
} FRIENDLY TECHNOLOGY

Pranjali Kulkarni

Govt. Girls P.G. College, Ujjain (M.P.)

\begin{abstract}
As the technology develops and becomes widely acceptable, what is eco-friendly technology is a question that many people will be able to easily answer. However, time is need while often more researched need for monitoring the progress. There are some simple day to day things which we can do and become eco-friendly without using the high technology products. If your day-to-day actions are more environmentally-friendly you may not only help the environment, but you can benefit financially, physically and mentally as well. For example, getting rid of toxic chemicals in your home and using natural cleaners will cost less, it will cut down on the number of toxins you are exposing yourself and the environment to and it will have a more positive impact on your indoor air quality. Hence going green is the new way to satisfy your needs, and now that the ecofriendly minds and products get their much awaited attention, this is the perfect time to bring in some eco-friendly techniques in our daily life to make our mother earth clean and a place to live in.

Keywords:

Environmental, eco-friendly technology, green.
\end{abstract}

\section{INTRODUCTION}

While global warming is becoming an increasing threat, plastic and other non-biodegradable waste materials are choking the planet, we can't just ignore what's happening by being just mute spectators. Going green is the need of the hour. Thankfully, due to the emergence of "eco-friendly technology" and "green technology" we can render our effective contribution in making the planet greener and sustainable.

Eco-friendly technologies involved making use of alternative energy source which is abundant to generate renewable energy, reducing the amount of resource which is limited used through the conventional like fossil fuel. For example renewable resources like sunlight, sea water and co2 which are abundant generating alternative resource like bio fuel, solar energy, freshwater and air purification through greenhouse, vegetation and halophytes cultivation stabilize the degraded desert soil and as wind breaks reduce the impact of pollutants on the environment. Apart from being eco-friendly, the concepts of green technology have made life simpler. They also have a lifestyle quotient. Think about this: When was the last time you stood in a long queue to pay your phone bill? Do you have the faintest recollection of writing your last letter? What's more, you can even shop while sitting on your living room sofa and book rail and air tickets. Green 
technology has not only helped in bringing down pollution levels but has also helped us in saving our precious time (in a world where time is a scarce resource).

The 21 st century has been more about environment and ecofriendly technologies. Environment conscious consumers are shifting to ecofriendly technologies and sustainable lifestyle. Companies are being mandated to use eco-friendly technologies with governments passing strict regulations on manufacturing practices. With all the reforms happening in the energy sector, it is only natural that new green technologies will emerge to satisfy the green part of the energy sector. Some of the big companies like HP and Apple are strictly following the recycling programs to reduce landfills and pollution.

In some areas of green technologies such as water recycling and purification through natural less destructive renewable methods used for sea water in the dessert environment is not burden with the waste while creating opportunity to produce various products afresh. These are also cheaper as well as using these waste materials recycle it in order to produce the new goods and products. This makes eco technologies cheaper for the producer and manufacturer in the long run. This is because though you may not see the savings right away when you start using sustainable technologies, you will realize that the money you save long term will be quite substantial.

Using biodegradable materials can be advantage for the reducing waste and impact to the environment and the human body. These materials having multiples characteristic making electronics circuits, tiny, flexible, stretchable and capable of dissolvable completely or partially enable us keeps our earth sustainable through reducing the amount of electronic waste polluting the landfill. Scientist like Professor John Roger and his working universities has announced making electronic component having disappearing act, and capable being completely vanish or partially disappear benefit health and the environment possible opportunities improving lifestyle and our environment. However, research and qualification and certification are required to get product approved.

Sustainable agriculture ensures that agricultural goods and products produced have fewer chemicals and are more organic whilst maintaining healthier soil quality and nutrients through various methods like recycling, rotating crops, composting replenishing nutrients and prevent pest through biological control reduce use of synthetic pesticides and fertilizer.

The greatest benefits of knowing what eco-friendly technology are the environment is choosing to use product that made from material preserved the environment and therefore does not degenerate at a fast rate. This is because when there is less waste produces, during the manufacture or production of products and the energy used is renewable which is less stressful on the environment there is less pollution and polluting chemicals and other substances. Jute fiber is an example having many areas for use and leaving minimal waste to the environment.

\section{How to Become Eco-friendly in your day-to-day life:-}

- 3 R's of Waste Hierarchy: The 3 R's of waste hierarchy can reduce the amount of waste generated and improve the waste management processes. Reducing what is produced and what is consumed can reduce the amount of waste that is generated. Reuse items for different purposes instead of disposing them off. Recycle items like aluminium cans, plastic, paper, glass that can be shaped into a new item.

- Conserve Water and Electricity: It takes energy to produce fresh water and electricity. Few simple ways like turning off lights when not in use, fixing leakages, proper insulation, using maximum daylight, installing energy efficient windows, purchasing energy efficient gadgets can reduce your daily energy consumption. 
- Plant More Trees: We all know why we need more trees on this planet. They give us oxygen, fruits, timber, prevent soil erosion, control floods, and provide shelter to wildlife. Massive scale deforestation in last couple of decades has reduced forest area by significant percentage. The need of hour is to work with environmental groups to educate more people and plant more trees so as to make this planet clean and eco-friendly.

- Protect Local Water Sources: Hazardous waste materials like paint, oil, ammonia and other strong chemical solutions should never be disposed on the ground as they'll seep into the groundwater. Join local water conservation groups and fight against water polluters who dump their industrial waste in rivers.

- Drive Less, Walk More: A simple and yet more effective way to live eco-friendly life is to either take public transportation for your daily commuting needs or try pooling in with your office colleagues to save fuel and reduce your carbon footprint. If your office is couple of miles away from home, you can either start half an hour early and walk on foot or ride a bicycle. If you're an avid traveler, you can follow these green travel tips.

- Buy Energy Efficient Products: Energy efficient products with 5 start energy rating consume less energy and prove to be eco-friendly. For instance, CFL bulbs consume $40 \%$ less energy and last 10 times longer than traditional bulbs.

- Buy locally Grown Products: When you buy or produce locally grown products, you are actually reducing your carbon footprint in the form of using less plastic bags, saving fuel to get vegetables from the market, using less packaged material . Apart from this, you can also sell surplus to your friends or relatives.

- Prevent Littering: Litter can originate from construction and demolition sites, households, industries, uncovered trucks, pedestrians, and moving vehicles. Littering can have big impact on environment, wildlife and local tourism industry. Being a responsible citizen, it's our responsibility to make our cities clean and impart same education to our kids.

- Buy Recycled Products: Always look out for recycling symbol when you visit grocery shop to buy items for your home. That will make you environmentally responsible and ecofriendly. Also, try to carry grocery bag with you to avoid buying items in plastic bags that will later end up in landfills.

- Join Environmental Groups to Combat Pollution: Protecting mother Earth is everyone's responsibility including you. The best you can do is to join different environmental groups in your city and provide helping hand to make this planet environmentally friendly. 